\title{
A Comparative study of the results of conservative treatment versus closed titanium elastic nailing for fractures of shaft of femur in children
}

\author{
Kunal Subhas Mukherjee ${ }^{1}$, Amar Nath Gupta ${ }^{2}$ \\ ${ }^{1}$ Assistant Professor, Department of Orthopedics, ${ }^{2}$ Assistant Professor, Department of Anaesthesia, Gouri Devi Institute \\ of Medical Sciences, Durgapur, West Bengal
}

Background: The ideal treatment of femoral shaft fracture in children is defined as one that controls alignment and length, is comfortable for child and convenient for family and causes the least psychological impact possible. Aims and Objective: The current study was designed to evaluate outcomes prospectively in the first year following treatment of a diaphyseal femoral fracture in children between five and ten years of age treated randomly either by intramedullary titanium elastic nailing or by traction followed by spica cast. Materials and Methods: Out of 48 cases selected according to inclusion/exclusion criteria 6 patients were lost to follow up. Among the rest of 42 patients, 23 were treated by intramedullary titanium elastic nailing and the other 19 conservatively by surface traction. The patients were evaluated at the regular interval of $2,4,6$ and $8^{\text {th }}$ week post operatively and thereafter every month. Results: There was a significant difference $(p<0.001)$ in terms of mean hospital stay and mean weight bearing between the two study groups. The findings of outcome and maintenance of reduction, time taken for the evidence of union to appear, the range of movements, the time when weight bearing can be allowed, the functional return of the limb, the rate of complications and the number days of hospital stay were comparable to similar studies conducted earlier. Conclusion: The study concludes that closed pediatric femoral shaft fractures within the ages of 5-10 years can be treated successfully by any methods of traction followed by spica cast or intramedullary titanium elastic nailing. However, because of shorter immobilization period and earlier ambulation, internal fixation with titanium elastic nailing is recommended as the better choice to treat this fracture in school going children.

Key words: Titanium elastic nailing, Traction, Spica cast, Fracture femur, Children
Access this article online

Website:

http://nepjol.info/index.php/AJMS DOI: $10.3126 /$ ajms.v8i4.17248

E-ISSN: $2091-0576$

P-ISSN: 2467-9100

\section{INTRODUCTION}

Femoral shaft fractures, including subtrochanteric and supracondylar fractures, represent approximately $1.6 \%$ of all bony injuries in children. The male to female ratio of femoral fracture is $2.6: 1$ with a bimodal distribution. ${ }^{1,2,3}$

The etiology of femoral fractures in children varies with the age of the child. In children younger than walking age, up to $80 \%$ of femoral fractures may be caused by abuse. ${ }^{4,5,6}$ In older children, femoral fractures are most likely to be caused by highenergy injuries, such as motor vehicle accidents, which account for over $90 \%$ of femoral fractures in this age-group. ${ }^{2,7,8}$

A review of the Maryland Hospital Discharge Database by Hinton et $\mathrm{al}^{9}$ confirmed the bimodal distribution with peak incidences at 2 and 12 years of age. The annual rate of femoral shaft fracture in children was 1 per 5,000. In Switzerland, the incidence of pediatric femoral shaft fracture is 1 per 2,000 per year. ${ }^{10}$ 
Waddell's triad of femoral fracture, intra-abdominal or intrathoracic injury, and head injury are associated with high-velocity automobile injuries. Multiple traumas may necessitate rapid stabilization of femoral shaft fractures ${ }^{11,12}$ to facilitate overall care. This is particularly true with head injury and vascular disruption.

The hemodynamic significance of femoral fracture has been studied by two groups. ${ }^{13,14}$ Hematocrit levels below $30 \%$ rarely occur without multisystem injury. A declining hematocrit should not be attributed to closed femoral fracture until other sources of blood loss have been eliminated. ${ }^{13,14}$ The most common femoral fracture in children (over 50\%) is a simple transverse, closed, non comminuted injury.

In children who are five years of age or younger, early closed reduction and application of a spica cast is an ideal treatment for most diaphyseal femoral fractures. ${ }^{15}$ In skeletally mature adolescents, use of an antegrade solid intramedullary rod has become the standard of treatment. ${ }^{16,17}$ The best treatment for children between six and sixteen years of age is still debated. ${ }^{16,18}$ Various operative methods have been used in this age-group to avoid the adverse physical, social, psychological, and financial consequences of prolonged immobilization; these methods include external fixation, ${ }^{19,20}$ plates and screws ${ }^{21,22}$ and use of a solid antegrade intramedullary nail. ${ }^{23,24}$ However, the risk of certain complications, particularly pin-track infection and refracture after external fixation or osteonecrosis after fixation with a solid antegrade intramedullary nail, has prevented these methods from becoming widely utilized. ${ }^{16,23}$ Fortunately, regardlessof the treatment method, the vast majority of children witha diaphyseal femoral fracture have an excellent long-term result.

Comparative studies and retrospective reviews have demonstrated unsatisfactory results in a small, yet significant, percentage of patients treated with skeletal traction. ${ }^{25,26}$ It is clear that traction remains an acceptable method of treatment of femoral shaft fractures in children under 12 years of age, but surgical methods are easier or more convenient with similar outcome.

The comparative economics of nonoperative and operative treatment of femoral shaft fractures have been evaluated by several researchers ${ }^{27,28}$ but no clear consensus has been reached. Until now, a variety of treatment methods have been used, but none of them is the standard method. In the past, almost all of these fractures have been treated conservatively by traction and spica cast and now this method also is being used for younger children only. ${ }^{29}$
Therefore this study was planned to compare the achievement and maintenance of reduction, time taken for the evidence of union to appear, the range of movements, the time when weight bearing can be allowed, the functional return of the limb, the rate of complications and the number days of hospital stay following conservative treatment vis a vis closed intramedullary titanium elastic nailing in cases of fractures shaft femur in children.

\section{MATERIALS AND METHODS}

After prior approval from the institutional ethics committee a randomized parallel group comparative study was done on children of either sex between 5 - 10 years presenting with closed fracture shaft femur and Gustillo Type I wound attending attending either emergency or orthopedics outdoor or patients referred from peripheral hospitals were selected during July 2008 to August 2010 in a Tertiary Care Hospital of Eastern India. Patients with Gustillo type II and type III open fractures of shaft femur, with an active infection, pathological fractures, abnormal medullary cavity, having distal neurovascular deficit and having any associated major injury (head injury, intra abdominal injury, intra thoracic injury, any associated other long bone fracture) were excluded from the study. A total of $(n=48)$ patients were recruited based on inclusion/exclusion criteria out of which 6 were lost during follow up of the study.

On admission a rapid general assessment of the patient was ascertained as a first step and any life threatening conditions were addressed and treated with due attention. The "ABC's" of initial management (A- Airway, B- Breathing and C- Circulation) were addressed. If the patient was found in shock due to trauma, pain or undue haemorrhage then it was properly managed with analgesic and intravenous infusion or transfusion of blood as and when required. Next the patients were assessed for soft tissue injury, blood supply of the injured area and extension of bony injury. Written informed consent were obtained from close relative of the patient. The positive responders were randomized according to online random number generated by (www. random.org) into either the conservative treatment group (traction followed by spica cast) or intramedullary titanium elastic nailing group.

All relevant pre operative investigations were done and proper pre anaesthetic check up was carried out by trained personnel for all study participants. All the operations of the study participants were carried out by a single trained and qualified orthopaedic surgeon and his assistants to avoid any performance or skill related bias. 
In patients of intramedullary titanium elastic nailing group, the width of the canal was measured at the narrowest point in the diaphysis on both the antero - posterior(AP) and lateral views of skiagram, and this number was divided by 2 . This represents the maximal diameter of titanium elastic nail that can be used, and generally a nail $0.5 \mathrm{~mm}$ smaller than this radius was used filling approximately $80 \%$ of the canal diameter.

The distance from the top of the inserted nail to the level of the fracture site was measured, and a gentle 30-degree bend was placed in the nail with the apex at what will be the level of the fracture. The nails used generally were 3.0 to $4.0 \mathrm{~mm}$ in diameter, depending on the size of the bone and the child. Two nails of the same size were always used, and varying sizes were avoided.

The operations were carried out with the patient in the supine position and the table was positioned such that the $\mathrm{C}$-arm could be brought beneath the table. The affected limb is prepared and draped with the thigh (hip to knee) exposed. The image intensifier was used to localize the placement of skin incisions by viewing the distal femur in the AP and lateral planes. Incisions were made on the medial and lateral side distal to the insertion site in the bone. The proximal end of the $3 \mathrm{~cm}$ incision was at or just distal to the level of the insertion site, which is about 2.5 to $3 \mathrm{~cm}$ proximal to the distal femoral physis. An awl was used to make a cortical hole in the bone. The distal femoral metaphysis was opened using an awl at a point $2.5 \mathrm{~cm}$ proximal to the distal femoral physis. The awl was then inclined 10 degrees anteriorly and steeply angled in the frontal plane to facilitate passage of the nail through the dense pediatric metaphyseal bone. Titanium elastic nails were inserted from the medial and lateral side and driven up to the level of the fracture. Upon insertion the nail glances off the cortex as it advances toward the fracture site. Both medial and lateral nails were inserted to the level of the fracture. At this point the fracture was reduced using longitudinal traction. After the first nail was driven across the fracture, approximately 2 to $3 \mathrm{~cm}$, the second nail was driven across the fracture. The two nails then were driven into the proximal end of the femur, with one driven toward the femoral neck and the other toward the greater trochanter.

After the nails were driven across the fracture and before they were seated, fluoroscopy was used to confirm satisfactory reduction of the fracture and to ensure that the rods did not comminute the fracture as they were driven into the proximal fragment. The nails were pulled back approximately $2 \mathrm{~cm}$, the end of each nails were cut, and the nails were driven back securely into the femur.
In the post operative period the stitches were removed on day 14 and for unstable long oblique fractures or comminuted fractures, immobilization with a long leg slab was done. Physical therapy with touchdown weight-bearing was begun as soon as the patient was comfortable, generally around $3^{\text {rd }}$ week. Then gentle knee exercises and quadriceps strengthening procedures were initiated. Full weightbearing generally was given by the start of $8^{\text {th }}$ week. The patients were kept under follow up. Nails were removed when the fracture line was no longer visible in radiograph, which typically seen between $9-12$ months postoperatively.

The patients of the other group those receiving conservative treatment were given adhesive skin traction for 3 weeks, followed by hip spica cast. The malleolli and the fibular head were protected from pressure effect by a piece of cotton. Starting at the ankle, leaving a loop of $5 \mathrm{~cm}$ beyond the distal end of the limb, widest possible strapping was applied to each side of the limb. On lateral side the strapping lied slightly behind and parallel to a line between the lateral malleolus and the greater trochanter and on medial aspect lies slightly in front of the above line.

A crepe bandage was applied tightly over the limb. The limb was put on a rightly measured Thomas splint. Then the required traction weight was attached and traction was given through a bed pulley. After 3 weeks of traction, the skin traction was removed and a hip spica cast was applied. All patients were monitored for 24 hours after spica application for assessment of development of neurovascular compromise and/or compartment syndrome, if any.

In most cases, the cast was kept till 6-8 weeks after the injury. After the removal of the cast skin care and physical therapy with touchdown weight-bearing was initiated.

The patients were evaluated on 2, 4, 6 and $8^{\text {th }}$ week following operation and after that every month. At every visit the patients were assessed for clinical and radiological evidences of exact reduction and correct alignment of the fracture fragment, limb alignment and rotation, condition of the wound and skin. Clinical and radiological examinations were also done to assess fracture union, the range of motion of the hip and knee, limb length discrepancy, any pain or other symptoms.

\section{RESULTS}

A total of $(n=48)$ children mostly aged $7-8$ years (Figure 1 ) with fracture shaft of femur commonly right sided $(\mathrm{n}=22)$ i.e. $52.3 \%$, majority of which resulted from road traffic accident $(\mathrm{n}=31)$ were recruited in the study. A minimum 6 months of follow up was done and the maximum follow 
up period was 2 years. Out of 48 patients, 4 were lost to follow up and in 2 patients fracture site had to be opened thus excluded from the final statistical analysis. Remaining 42 patients [male $27(64.3 \%)$, female 15(37.3\%)] were considered for assessment and later evaluated. Out of the 42 patients, 23 patients were treated closed intramedullary titanium elastic nailing and 19 patients were treated traction followed by spica cast. The results were evaluated using Flynn et al scoring system. ${ }^{30}$

The most common type of fracture shaft of the femur found in the children was transverse followed by oblique (Figure 2). A total of $(n=23)$ patients who were treated by titanium elastic nailing had an average operation time of $65 \mathrm{mins}$. The patient's mean hospital stay was 8.5 days (5 - 16 days) against 26 days (24 - 31 days) in patients treated conservatively which was statistically significant $(\mathrm{p}<0.001)$. Radiological union was achieved in all cases of titanium elastic nailing in a mean time of 8.9 weeks ( $6-12$ weeks) against 9.5 weeks ( 8 -14 weeks) in the conservative managed group. Regarding full weight bearing after operation there was a significant difference between the two study groups (Table 1).

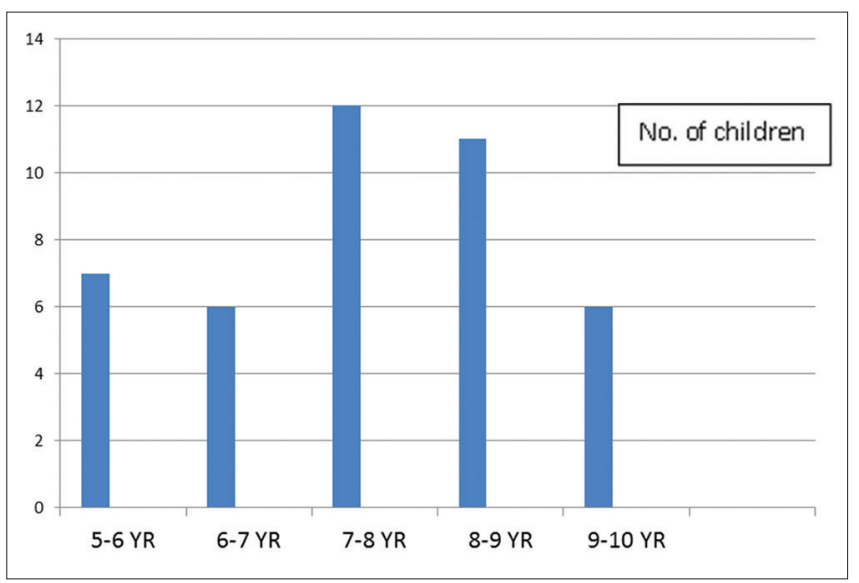

Figure 1: Distribution of patients according to age group

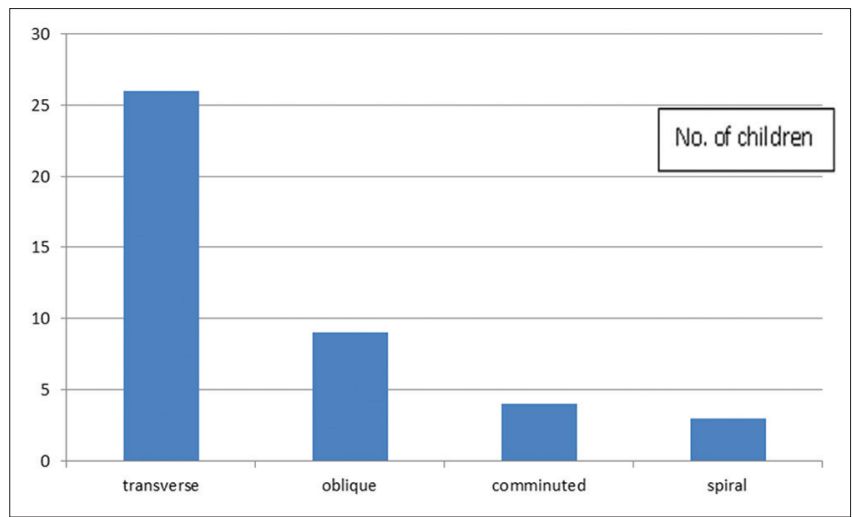

Figure 2: Distribution of type of fracture shaft of the femur in the study population
In the titanium elastic nailing group the nails used during the operation were removed after an average 11 month (9 -12 months) and there were no complications related to implantremoval. In the traction followed by spina cast group, two patients had valgus angulation $\left(18^{\circ}\right.$ and $\left.10^{\circ}\right)$, one patient had varus angulation of $15^{\circ}$, and one patient each with limb shortening of $2 \mathrm{~cm}$ and $1.5 \mathrm{~cm}$ respectively were noted. Two patients had a limb shortening complication of $0.5 \mathrm{~cm}$. In addition one patient had a substantial loss of reduction and was treated with re manipulation and spica cast. Two patient altogether had pressure sore due to plaster cast and one caseof severe knee stiffness requiring manipulation with the patient under anesthesia. Based on the criteria on the work by Kasser and Beaty, 38 (98.47\%) out of total 42 children had acceptable alignment at the time of union. One child treated with titanium elastic nailing and three children treated with traction and application of a spica cast had unacceptable angulation or inequality between the lengths of the lower extremities at the time of union. The overall outcome of both the management were analyzed as per the scoring criteria by Flynn et al ${ }^{30}$ and found to be insignificant with degree of freedom 2 and $\mathrm{p}=1.000$ (Table 2).

\section{DISCUSSION}

The ideal treatment of femoral shaft fracture in children is defined as one that controls alignment and length, is comfortable for child and convenient for family and causes the least psychological impact possible. In the present study, the children from 5-10 years of age were treated for femoral shaft fractures. Treatment of femoral shaft fracture in this age group is highly controversial.

Historically, femoral shaft fractures in children above 5 years and adolescents have been treated by non operative methods but the children of this age group tolerate the prolonged immobilization of traction less for physical, psychological and social reasons. For the last two decades the management of the femoral shaft fractures has evolved more towards the operative approach to decrease prolonged hospitalization and plaster complication. By internal fixation, the management of multiple traumas is made easier. This procedure tends to satisfy many of the parents of our patients who insisted upon a "Perfect alignment" at initial treatment and will not accept any overriding of the bones even when reassured that overriding will correct itself with time.

Until recently, skeletal traction and application of a cast was the preferred method for treatment of diaphyseal femoral fractures in children and young adolescents. This method stood the test of time because it was relatively conservative 
Table 1: Comparison of treatment outcomes among the study group

\begin{tabular}{lccc} 
Assessment parameters & Titanium elastic nailing $(\mathbf{n = 2 3 )}$ & Traction and spica cast $(\mathbf{n}=\mathbf{1 9})$ & Significance $(\mathbf{p}$ value) \\
\hline Mean hospital stay & 8.5 days & 26 days & $p<0.0001$ \\
Radiological union & 8.9 weeks & 9.5 weeks & $p=0.2776$ \\
Full weight bearing & 9.1 weeks & 11.5 weeks & $p<0.0001$ \\
\hline
\end{tabular}

\begin{tabular}{|c|c|c|}
\hline Score & $\begin{array}{c}\text { Titanium elastic } \\
\text { nailing }(n=23)\end{array}$ & $\begin{array}{c}\text { Traction and } \\
\text { spica cast }(n=19)\end{array}$ \\
\hline Excellent & $16(69.5 \%)$ & $11(58 \%)$ \\
\hline Successful & $6(26 \%)$ & $6(31.5 \%)$ \\
\hline Poor & $1(4.5 \%)$ & $2(10.5 \%)$ \\
\hline
\end{tabular}

and permanent complications impairing future function were rare. However, orthopedists increasingly have tried a variety of methods to avoid prolonged immobilization.

For more than two decades, French surgeons have used titanium elastic nails to achieve stable intramedullary fixation Recently, titaniumelastic nails have become widely available in India. An initial multicenter study by Flynn JM et $\mathrm{al}^{30}$ showed excellent or satisfactory results in fifty-seven of fifty-eight cases treated with such nails.

Our current study was designed to evaluate outcomes prospectively in the first year following treatment of a diaphyseal femoral fracture either by using titanium elastic nail or traction followed by spica cast in children between five and ten years of age. The focus of this study was the treatment and recovery period. Attempt to determine the long-term results of treatment with titanium elastic nails or skeletal traction and a spica cast were not made since the long-term result after a diaphyseal femoral fracture in this age-group is almost always satisfactory, regardless of which of several methods is used for treatment. With the focus on the first year, we cannot comment on the exact final lower-extremity length and alignment of each child.

In comparison to study by Flynn JM et $\mathrm{al}^{30}$ which showed $8.5 \%$ unacceptable outcome in patient treated with traction and spica cast, and no unacceptable outcome in patient treated with titanium elastic nailing, our current study showed 15.8\% unacceptable outcome in patient treated with traction followed by spica cast, and $4.3 \%$ unacceptable outcome in patient treated with titanium elastic nailing. The time taken for full weight bearing was longer in comminuted or spiral fracture, irrespective of treatment method.

In the present study surface traction was adopted as the form of conservative treatment, whereas Flynn et $\mathrm{l}^{30}$ used skeletal traction in conservatively treated patients. This could be a factor giving poorer result of conservatively treated patient in our study.

In a similar study in India by M.N.Gupta et $\mathrm{al}^{32}$ their findings were comparable with the current study in all the assessed parameter.

\section{CONCLUSION}

The present study was conducted with a very small population at a tertiary care hospital in the eastern part of India. The study concludes that closed pediatric femoral shaft fractures within the ages of 5-10 years can be treated successfully by any methods of traction followed by spica cast or intramedullary titanium elastic nailing. However, because of shorter immobilization period and earlier ambulation, internal fixation with titanium elastic nailing is recommended as the better choice to treat this fracture in school going children. Perhaps broader patient based randomized controlled research with modified design might strengthen the findings of the current study.

\section{REFERENCES}

1. Fry $\mathrm{K}$, Hoffer MM and Brink J. Femoral shaft fractures in braininjured children. J Trauma 1976; 16:371-373.

2. Hedlund $R$ and Lindgren $U$. The incidence of femoral shaft fractures in children and adolescents. J Pediatr Orthop 1986; 6:47-50.

3. Landin LA. Fracture patterns in children: analysis of 8,682 fractures with special reference to incidence, etiology and secular changes in a Swedish urban population 1950 â€"1979. Acta Orthop Scand Supp 1986; 202:54.

4. Beals RK and Tufts E. Fractured femur in infancy: the role of child abuse. J Pediatr Orthop 1983; 3:583-586.

5. Gross $\mathrm{RH}$ and Stranger M. Causative factors responsible for femoral fractures in infants and young children. J Pediatr Orthop 1983; 3:341-343.

6. Silverman FN. Radiological aspects of the battered child syndrome. In The Battered Child. Edited. University of Chicago Press; 1987:214-246.

7. Daly KE and Calvert PT. Accidental femoral fracture in infants. Injury 1991; 22:337-338.

8. Loder RT. Pediatric polytrauma: orthopaedic care and hospital course. J Orthop Trauma 1987;1:48-54.

9. Hinton RY, Lincoln A, Crockett MM, Sponseller P and Smith G. Fractures of the femoral shaft in children: incidence, mechanisms, and sociodemographic risk factors. J Bone Joint Surg Am 1999; 81(4):500-509.

10. Buess $E$ and Kaelin $A$. One hundred pediatric femoral fracture: epidemiology, treatment attitudes, and early complications. 
J Pediatr Orthop Br 1998; 7:186-192.

11. Loder RT. Pediatric polytrauma: orthopaedic care and hospital course. J Orthop Trauma 1987; 1:48-54.

12. Porat S, Milgrom, C, Nyska M, Whisler JH, Zoltan JD and Mallin BA. Femoral fracture treatment in head-injured children: use of external fixation. J Trauma 1986; 26:81-84.

13. Ciarallo $L$ and Fleisher $G$. Femoral fractures: are children at risk for significant blood loss? Pediatr Emerg Care 1996; 12:343-346.

14. Lynch JM, Gardner MJ and Gains B. Hemodynamic significance of pediatric femur fractures. J Pediatr Surg 1996; 31:1358-1361.

15. Kasser JR and Beaty JH. Femoral shaft fractures. In: Beaty JH Kasser JR, editors. Rockwood and Wilkins' fractures in children. $5^{\text {th }}$ ed. Philadelphia: Lippincott Williams and Wilkins; 2001: 941-980.

16. Flynn JM, Skaggs D, Sponseller PD, Ganley TJ, Kay RM and Leitch KK. The operative management of pediatric fractures of the lower extremity. J Bone Joint Surg Am 2002; 84: 2288 -2300.

17. Stans AA, Morrissy RT and Renwick SE. Femoral shaft fracture treatment in patient's age 6 to 16 years. J Pediatr Orthop 1999; 19:222 -228.

18. Sanders JO, Browne RH, Mooney JF, Raney EM, Horn BD, Anderson DJ, et al. Treatment of femoral fractures in children by pediatric orthopedists: results of a 1998 survey. J Pediatr Orthop 2001; 21: 436-441.

19. Aronson $\mathrm{J}$ and Tursky EA. External fixation of femur fractures in children. J Pediatr Orthop 1992; 12:157-163.

20. Tolo VT. External skeletal fixation in children's fractures. J Pediatr Orthop 1983; 3:435-442.

21. Kregor PJ, Song KM, Routt ML, Sangeorzan BJ, Liddell RM and Hansen ST. Plate fixation of femoral shaft fractures in multiply injured children. J Bone Joint Surg Am 1993; 75:1774 - 1780.

22. Ward WT, Levy J and Kaye A. Compression plating for child and adolescent femur fractures. J Pediatr Orthop 1992; 12:626 -632.
23. Beaty JH, Austin SM, Warner WC, Canale ST and Nichols L. Interlocking intramedullary nailing of femoral-shaft fractures in adolescents: preliminary results and complications. J Pediatr Orthop 1994; 14:178 -183.

24. Buford D, Christensen $K$ and Weatherall P. Intramedullary nailing of femoral fractures in adolescents. Clin Orthop 1998; 350:85-89.

25. Humberger FW and Eyring EJ. Proximal tibial $90 a ̂ €$ "90 traction in treatment of children with femoral-shaft fractures. J Bone Joint Surg Am 1969; 51:499-504.

26. Herndon WA, Mahnken RF, Yngve DA and Sullivan JA. Management of femoral shaft fractures in the adolescent. J Pediatr Orthop 1989; 9:29-32.

27. Reeves RB, Ballard RI and Hughes JL. Internal fixation versus traction and casting of adolescent femoral shaft fractures. J Pediatr Orthop 1990; 10:592-595.

28. Newton PO and Mubarak SJ. Financial aspects of femoral shaft fracture treatment in children and adolescents. J Pediatr Orthop 1994; 14:508-512.

29. Ferguson $\mathrm{J}$ and Nicol RO. Early spical treatment of pediatric femoral shaft fractures. J Pediatr Orthop 2000; 20:189-192.

30. Flynn JM, Hresko T, Reynolds RA, Blasier RD, Davidson R and Kasser J. Titanium elastic nails for pediatric femur fractures: a multicenter study of early results with analysis of complications. J Pediatr Orthop 2001; 21(1):4-8.

31. Kasser JR and Beaty JH. Femoral shaft fractures. In: Beaty JH, Kasser JR, editors. Rockwood and Wilkins' fractures in children. $5^{\text {th }}$ ed. Philadelphia: Lippincott Williams and Wilkins; 2001: $941-80$

32. Gupta MN, Salaria AQ, Gupta R, Sharma S, Bala S and Basit MA. Treatment of fracture shaft of femur in children (A comparative study of operative versus conservative management). JK-Practitioner 2007; 14(1):28-30.

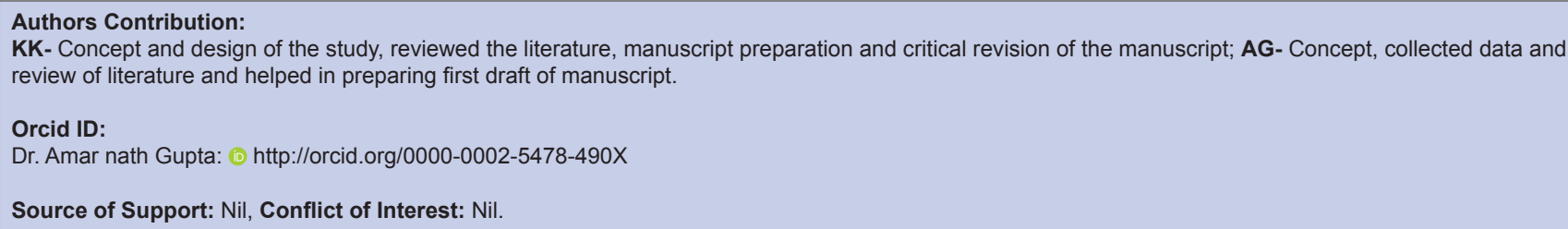

